\title{
AVERAGE CHARACTERISTICS OF CYLINDRICAL STATOR 6/2 SWITCHED RELUCTANCE GENERATOR
}

\author{
F. M. El-Kholy* and A. F. Abdel-Kader** \\ ${ }^{*}$ Electrical Engineering Department, Faculty of Engineering, Minoufiya University, Egypt \\ ** Agriculture Ministry, Tanta Strip, Egypt
}

\begin{abstract}
The switched reluctance motor can be used in generation mode by selecting the firing angles of the phases current. Switched reluctance generators (SRG) have been identified as a potential option for military aircraft, variable speed wind turbine and automotive electric power systems. (SRG) has various desirable features which include simple and solid structure, easiness of maintenance, small moment of rotor inertia and low cost.

This paper presents detailed average characteristics of a $6 / 2$ cylindrical stator (SRG). The suitable control for maximum energy conversion in SRG is obtained. The excitation converter is arranged for continuity of load phases current. The results are computed from the average analysis equations.

Maximization of power throughout of (SRG) has been addressed in this paper. Phase selfinductance, phase voltage switching angles, DC bus voltage level and shaft speed of the generator have been identified as generator parameters and control variables affecting output power. Depending on the application each one of these parameters can be defined as either generator parameter or control variable. Due to highly nonlinear characteristics of (SRG), the analytical equation for output power in terms of generator parameters and control variables is complicated. So, iterative simulation of the generator model on the range of generator parameters and control variables has been used for finding output power profile.

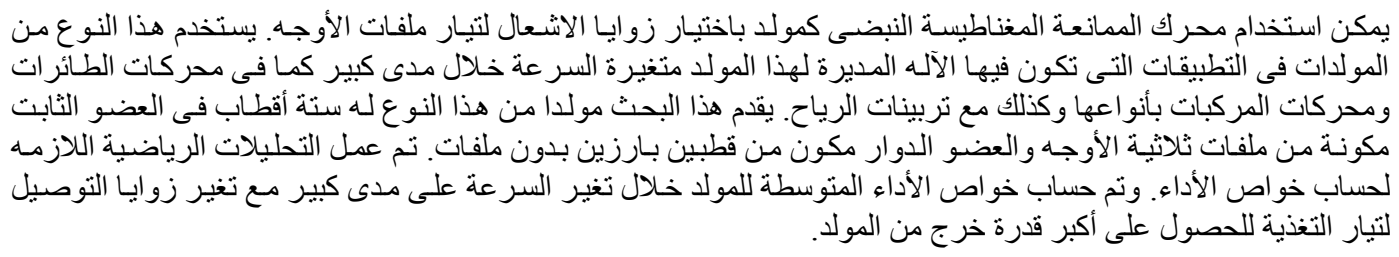

Keywords: Reluctance generator, Generator control, Wind energy generator, Aircraft generator, automotive generator, Variable speed generator

\section{INTRODUCTION}

A starter / generator is directly driven by a gas turbine engine. Because of its ability to operate at high speeds and temperatures, it can be located internally or in close proximity to the engine, without the need for a gearbox or pulley and belt system. Incorporate switched reluctance machine technology, which offers: high speed structure eliminates permanent magnets and conductors in the rotor. High temperature design uses special insulation system for coil windings and is not limited by the operating temperature of permanent magnets or composites [13]. High efficiency, inherent fault tolerance are obtained with three or more independent electrical phases. Magnetic structure reduces the size and weight of the machine and its associated electronics. Improved vibration control and support of shaft, magnetic structure and control algorithm improve the dynamic performance of the turbo machine [4-6].

The SRG is a highly reliable machine as it can function even under faulty conditions with reduced performance. One of the reasons for this is that the rotor does not have any excitation source and thus does not generate power into the faulted phase; therefore, no sparking / fire hazards due to excessive fault currents [7-9]. The classic SRG drive as a system with converter involves two switches and a winding in series. Thus, even in a case of both switches being turned on at the same time, no shootthrough faults would occur, unlike the case of AC drives, which lead to shorting of the DC bus. 
Electromagnetic torque in the SRM is produced by the tendency of the salient rotor poles to align with the excited stator poles and attain the least reluctance position. The torque developed depends on the relative position of the phase current with respect to the inductance profile [10]. If the current falls on the negative slope of the inductance profile, then the machine is in the generating mode. The back EMF developed depends on the magnetic parameters of the machine, rotor position, and the geometry of the SRG.

The current waveforms for the motoring mode and the generating modes are mirror images of each other. During generation, initial excitation has to be provided from an external source, it being a single excited structure [11-12]. The stator coils are turned on around the aligned position and then turned off before un alignment for generating electricity. The turn-on and turn off angles as well as the current determine the performance of the machine. During the high-speed motoring mode, the peak value of the current depends on the turn-on time. These timings greatly help in designing optimal and protective control. In addition, in SRM, by changing the turn-on and turn- off angles, the system may be optimized to operate under maximum efficiency, minimum torque ripple, or minimum ripple DC link current. The extended constant power/speed ratio capability of the SRM enables less power requirement during the motoring mode.

The SRM can be current controlled for both motoring and generating modes of operation. During motoring the current is controlled by adjusting the firing angles and applying the current during the magnetization period. If during the current control there is overlapping of the phase currents, it leads to an increase in the maximum torque level. During the generation mode of operation, the torque must be fed to the machine when the inductance level is reducing, i.e., when the rotor is moving from the aligned position to the unaligned position.

\section{GENERATOR DESCRIPTION}

Stator is chosen to be cylindrical sheet poles, not salient poles. Stator is consisted of six poles. Each two opposite poles construct one phase. So, the stator consists of three phases A, B and C. There is 600 space angle between each phase and its adjacent phase as shown in Fig. (1). Generator data are given in the appendix.

The stator consists of silicon steel laminations and contains 36 slots, with $35-\mathrm{mm}$ axial length. This stator is the same as a stator of single phase induction motor, 1/3 HP, split phase type. This is rewound to suite the SRG performance. Dimensions of rotor are illustrated in Fig.(2).

The rotor has two salient poles without any winding. The rotor length has the same lamination length of stator. Width of pole arc to pole pitch is characterized by(pole arc / pole pitch). In order to decrease the harmonics of stator slots, the rotor is skewed by one stator slot pitch as shown in Fig.(2).

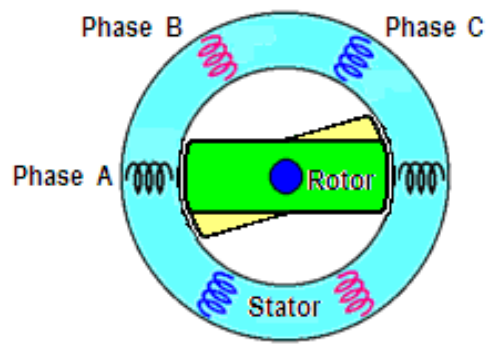

Fig. 1 Stator phases positions

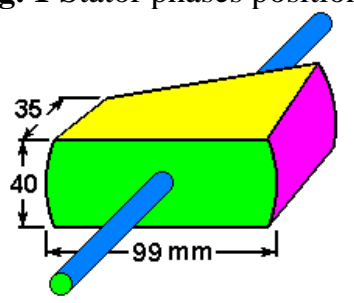

Fig. 2 Rotor

In order to simulate six poles in stator, the field concentration of each pole should be equal to rotor pole width. The stator windings are performed as shown in Fig. (3). Where the number of turns in each coil is equal to 150 turns, from copper wire with diameter of $0.45 \mathrm{~mm}$.

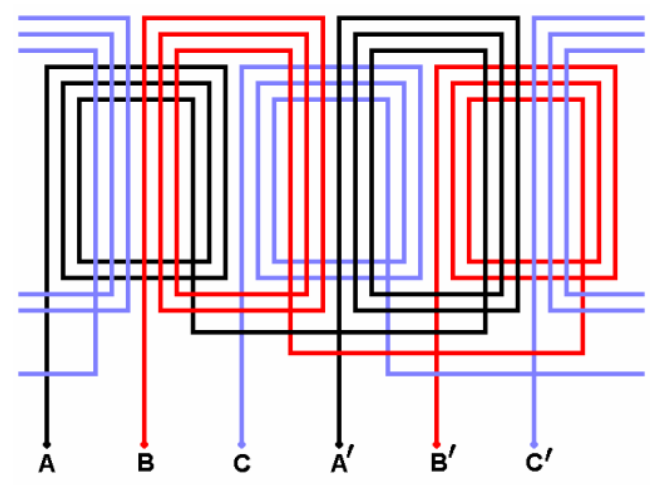

Fig. 3 Stator windings

\section{CONVERTER TOPOLOGY}

SRG drive converter should be able to magnetize phase coils, retrieve the generated power and demagnetize the phase coils in each cycle. An initial converter topology for this purpose is half bridge inverter [6-9]. For continuity of load phases current and higher load power, the load resistance is divided on the three phase as shown in Fig. 4. The current taken from the battery is called excitation current as shown in the appendix. 


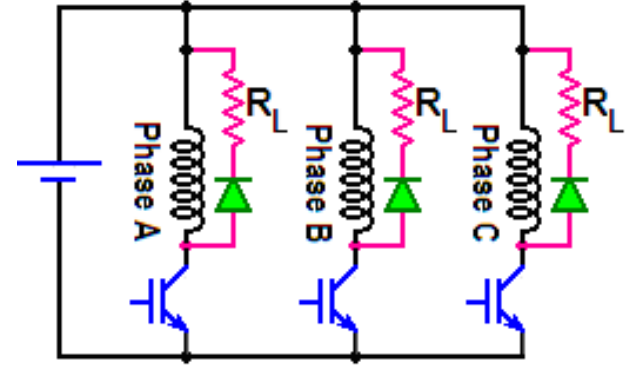

Fig. 4 Converter topology

\section{PERFORMANCE ANALYSIS}

\subsection{Phase Inductance Calculation}

The experimental generator phase self inductance is measured at different phase currents to give its variation due to rotor saliency. Neglecting the effect of saturation on the values of inductance, a suitable mean curve for each phase inductance is shown in Fig.(5).

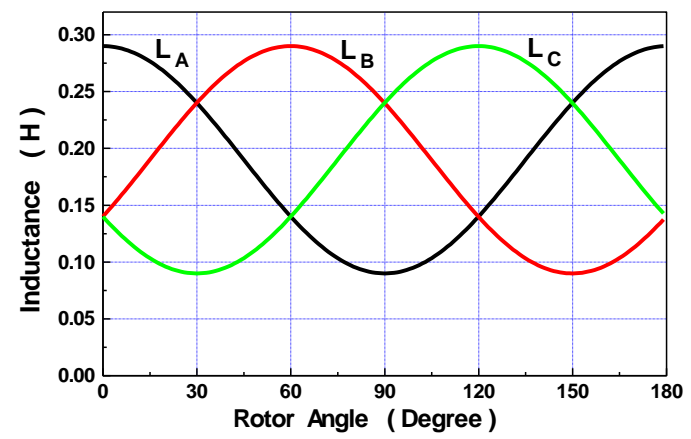

Fig. 5 Variation of generator inductances with rotor position

From this figure, the variation of inductance with rotor angle is nearly sinusoidal wave added to a constant value. Thus, the self inductance for each phase is determined from the following equations

$$
\begin{aligned}
& \mathrm{L}_{\mathrm{A}}=\mathrm{L}_{\mathrm{q}}+\mathrm{Lo}+\mathrm{Lo} \cos (2 \theta) \\
& \mathrm{L}_{\mathrm{B}}=\mathrm{L}_{\mathrm{q}}+\mathrm{Lo}+\mathrm{Lo} \cos \left(2\left(\theta+2 \theta_{\mathrm{S}}\right)\right) \\
& \mathrm{L}_{\mathrm{C}}=\mathrm{L}_{\mathrm{q}}+\mathrm{Lo}+\mathrm{Lo} \cos \left(2\left(\theta+\theta_{\mathrm{S}}\right)\right)
\end{aligned}
$$

Where;

$\mathbf{L o}=\left(\mathbf{L}_{\mathbf{d}}-\mathbf{L}_{\mathbf{q}}\right) / 2$;

$\mathbf{L}_{\mathbf{d}}$ is the stator phase inductance at aligned position; $\mathbf{L}_{\mathbf{q}}$ is the stator phase inductance at unaligned position;

$\boldsymbol{\theta}$ is the rotor position angle with respect to the axis of phase A;

$\boldsymbol{\theta}_{\mathbf{S}}$ is the angle between each two sequential stator phases $=60$ degree.

\subsection{Switching ON and OFF Angles}

In this paper, the switching OFF angle for any stator phase will be at the aligned position of the phase. The switching ON angle (alfa) is measured from the position before aligned position by 60 degree. Switching ON angle is varied from zero to 45 degree. For a switching ON angle (alfa) of 45 degree, the connection or excitation period will be $(60-45=15)$ degree.

\subsection{Generator Phase Voltage}

The voltage equation for each phase ( V ) of SRG is given $[4,5,9,10,12]$ by

$$
\mathrm{V}=\mathrm{I}_{\mathrm{ph}} \mathrm{R}_{\mathrm{ph}}+\{\mathrm{d} \lambda / \mathrm{dt}\}
$$

If the effects of saturation are neglected this expression can be rewritten as:

$$
\mathrm{V}=\mathrm{I}_{\mathrm{ph}} \mathrm{R}_{\mathrm{ph}}+\left\{\mathrm{d}\left(\mathrm{L}_{\mathrm{ph}} \mathrm{I}_{\mathrm{ph}}\right) / \mathrm{d} \mathrm{t}\right\}
$$

In generation mode equation (5) can be modified to the following form in which the even symmetry of the inductance profile is taken into account.

$$
\begin{gathered}
\mathrm{V}=\mathrm{I}_{\mathrm{ph}} \mathrm{R}_{\mathrm{ph}}+\left\{\mathrm{L}_{\mathrm{ph}}\left(\mathrm{dI}_{\mathrm{ph}} / \mathrm{dt}\right)\right\}+ \\
\left\{\omega \mathrm{I}_{\mathrm{ph}}\left(\mathrm{dL}_{\mathrm{ph}} / \mathrm{d} \theta\right)\right\}
\end{gathered}
$$

Where $\mathbf{V}_{\mathbf{p h}}, \mathbf{I}_{\mathbf{p h}}, \mathbf{L}_{\mathbf{p h}}, \boldsymbol{\omega}$ and $\mathbf{R}_{\mathbf{p h}}$ stand for phase voltage, phase current, phase inductance, speed and stator resistance, respectively.

Thus; the phase voltage ( $\mathrm{V}$ ) is;

$$
\mathrm{V}=\mathrm{I}_{\mathrm{ph}} \mathrm{R}_{\mathrm{ph}}+\mathrm{E}_{\mathrm{S}}+\mathrm{E}_{\mathrm{R}}
$$

Where; The phase self e.m.f. $\left(\mathbf{E}_{\mathbf{S}}\right)$ is calculated by

$$
\mathrm{E}_{\mathrm{S}}=\mathrm{L}_{\mathrm{ph}}\left(\mathrm{d} \mathrm{I}_{\mathrm{ph}} / \mathrm{d} \mathrm{t}\right)
$$

And the phase rotational e.m.f. $\left(\mathbf{E}_{\mathbf{R}}\right)$ is

$$
E_{R}=\omega I_{p h}\left(d L_{p h} / d \theta\right)
$$

\subsection{Average Phase Currents}

The instantaneous value of stator phase excitation current (Iph) during the excitation period is determined from the following equation;

$$
I_{p h}=I_{\max }\left[1-\mathrm{e}^{-(\mathrm{t} / \tau)}\right]
$$

Where;

$$
I_{\text {max }}=\left(V-E_{R}\right) / R_{p h}
$$

Therefore; the average excitation phase current ( $\mathbf{I}_{\text {exav }}$ ) is calculated by;

$$
I_{\text {exav }}=(1 / \pi) \int_{0}^{\pi}\left\{I_{\max }\left[1-e^{-(t / \tau)}\right]\right\} d \theta
$$

When the rotor angle $(\boldsymbol{\theta})$ is zero, the rotor is aligned with the axis of phase (A). The phase (A) will be switched off, its current is a load current $\left(\mathbf{I}_{\mathbf{L A}}\right)$ which will be flowing through the load resistance and is calculated by;

$$
\left.I_{L A}=I_{f} e^{-\left({ }_{A} / \tau\right.} A\right)
$$

Where;

$\mathbf{I}_{\mathbf{f}}$ is the higher instantaneous value of excitation current; 
$\mathbf{t}_{\mathbf{A}}$ is the time from the instant of phase (A) switched off ;

$\boldsymbol{\tau}_{\mathbf{A}}$ is the electrical time constant at any value of rotor angle, and

$\boldsymbol{\tau}_{\mathrm{A}}=\mathbf{L}_{\mathbf{A}} / \mathbf{R}$

The time $(\mathbf{t})$ is calculated at any value of $(\boldsymbol{\theta})$, starting from $\boldsymbol{\theta}=0$ by;

$$
\mathrm{t}=\theta /(6 \mathrm{~N})
$$

Where; $\mathbf{N}$ is the rotor speed.

The average load phase current $\left(\mathbf{I}_{\mathbf{L a v}}\right)$ is calculated by;

$$
\mathrm{I}_{\mathrm{Lav}}=(1 / \pi) \int_{0}^{\pi}\left\{\mathrm{I}_{\mathrm{f}} \mathrm{e}^{-(\mathrm{t}} \mathrm{A}^{/ \tau} \mathrm{A}^{\prime}\right\} \mathrm{d} \theta
$$

The average load phase A, B, C currents are symmetrical.

\subsection{Generator Power and Efficiency}

The prime mover torque is to compensate the generator torque occurred from the current passing through stator phases and the changing of rotor reluctance.

The instantaneous value of generator torque, resulting from each of three phases is determined as follows $[1,4,8,12]$;

$$
\begin{aligned}
& \mathrm{T}_{\mathrm{A}}=0.5 \mathrm{I}_{\mathrm{A}}^{2} \mathrm{~d} \mathrm{~L}_{\mathrm{A}} / \mathrm{d} \theta \\
& \mathrm{T}_{\mathrm{B}}=0.5 \mathrm{I}_{\mathrm{B}}^{2} \mathrm{~d} \mathrm{~L}_{\mathrm{B}} / \mathrm{d} \theta \\
& \mathrm{T}_{\mathrm{C}}=0.5 \mathrm{I}_{\mathrm{C}}{ }^{2} \mathrm{~d} \mathrm{~L}_{\mathrm{C}} / \mathrm{d} \theta
\end{aligned}
$$

The average generator torque $\left(\mathbf{T}_{\mathrm{av}}\right)$ is

$$
\mathrm{T}_{\mathrm{av}}=(1 / \pi) \int_{0}^{\pi}\left\{\mathrm{T}_{\mathrm{A}}+\mathrm{T}_{\mathrm{B}}+\mathrm{T}_{\mathrm{C}}\right\} \mathrm{d} \theta
$$

The average input mechanical power to the generator $\left(\mathbf{P}_{\text {mav }}\right)$ is calculated by;

$$
\mathrm{P}_{\text {mav }}=\mathrm{T}_{\mathrm{av}}(2 \pi \mathrm{N} / 60)
$$

The average value of generator excitation power $\left(\mathbf{P}_{\text {exav }}\right)$ is determined from the following equation:

$$
\mathrm{P}_{\text {exav }}=3 \quad \mathrm{~V} \quad \mathrm{I}_{\text {exav }}
$$

The generator average output power to the load $\left(\mathbf{P}_{\text {oav }}\right)$ is calculated by;

$$
\mathrm{P}_{\mathrm{oav}}=3 \mathrm{I}_{\mathrm{Lav}}{ }^{2} \mathrm{R}_{\mathrm{L}}
$$

The generator average efficiency ( $\boldsymbol{\eta}_{\text {av }}$ ) is calculated by;

$$
\eta_{\mathrm{av}}=\mathrm{P}_{\mathrm{oav}} /\left(\mathrm{P}_{\mathrm{exav}}+\mathrm{P}_{\mathrm{mav}}\right)
$$

\section{AVERAGE CHARACTERISTICS}

The average values of generator performance characteristics are computed (by BASIC programs) from equations (1 to 23) with speed variation, at excitation voltage of $500 \mathrm{~V}$ and a phase load resistance of $20 \mathrm{ohm}$.

Figure (6) illustrates the variation of generator average torque with speed. It is shown that, the torque at low speed is positive due to the motoring operation. The machine operating as a generator when the speed is higher than the no load speed of motoring mode ( at zero torque). When the switching $\mathrm{ON}$ angle (alfa) is zero, the generating mode starting at higher speed than with alfa $=45$. Therefore, this type of generators should be operated at higher speeds for good characteristics. Negative torque is required during generating mode. The generating torque is varied as shown in Fig. 6.

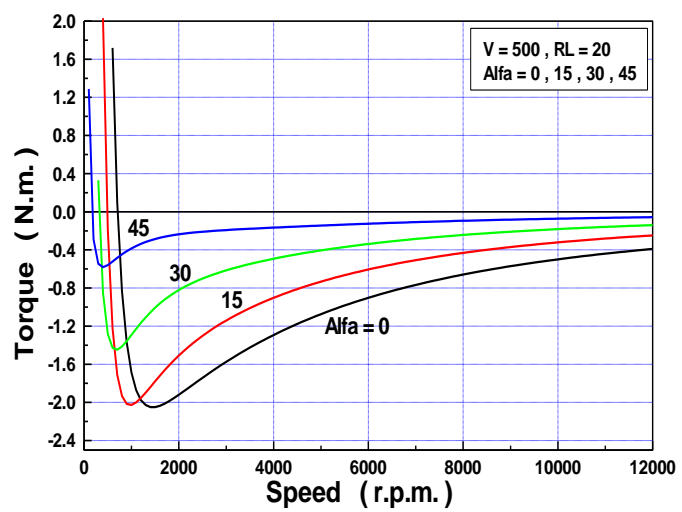

Fig. 6 Generator torque variation with speed at different values of switching $\mathrm{ON}$ angle

The phase winding current consists of both excitation and load currents. Variation of phase current with speed is shown in Fig. 7. Generator rated phase current is $3 \mathrm{~A}$. The phase current is higher than its rated value at lower speeds and should be limited. The increasing of switching ON angle (alfa) decreases phase current at any speed. When (alfa) equals 45 , phase current will be within rated value. Increasing speed decreases the phase current.

Excitation current variation with speed is shown in Fig. 8. This current is decreased by speed increasing, due to the decreasing of conduction period.

Load current variation with speed is shown in Fig. 9. Small variation of this current is occurred by speed variation due to the opposite effect of both excitation current and speed. Increasing (alfa), reduces load current.

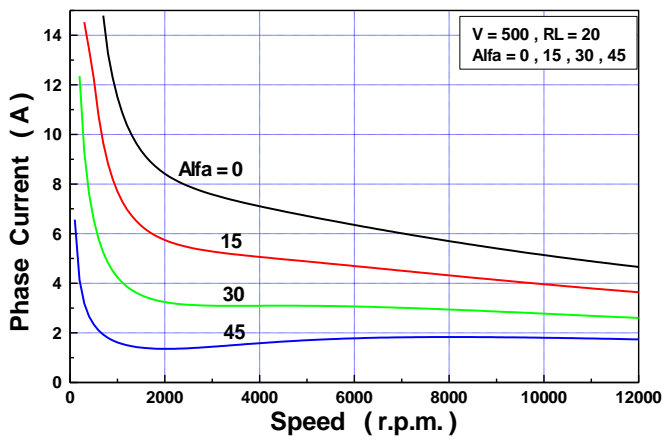

Fig. 7 Generator phase current variation with speed at different values of switching $\mathrm{ON}$ angle 


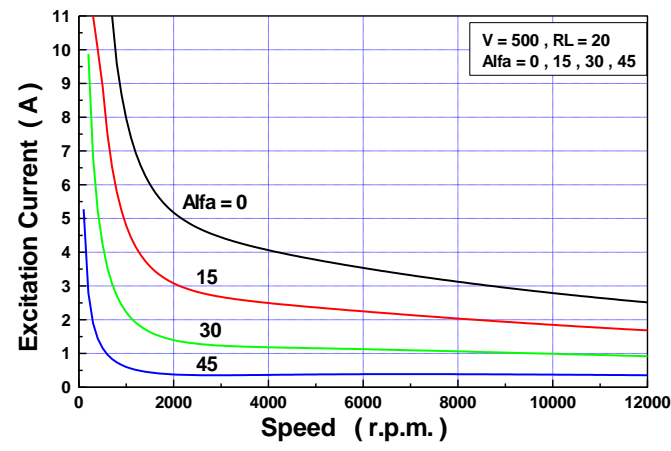

Fig. 8 Generator excitation current variation with speed at different values of switching ON angle

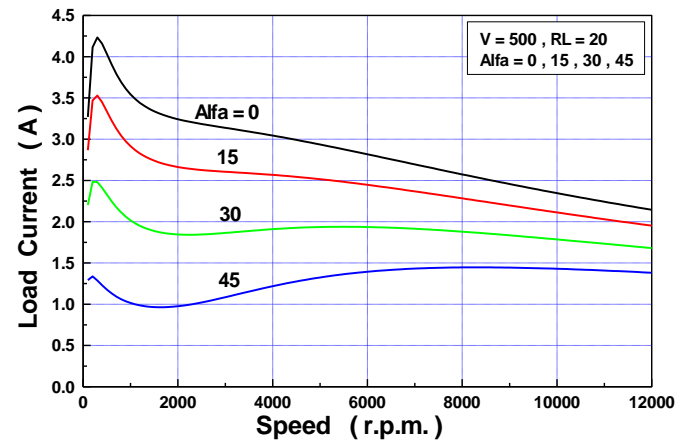

Fig. 9 Generator load current variation with speed at different values of switching $\mathrm{ON}$ angle

Load voltage variation with speed is shown in Fig. 10. At high values of (alfa) which are preferred, the load voltage (for constant load resistance) is nearly constant through a very wide range of speed. This is mainly due to the automatic decreasing of the excitation current through speed increasing. This is the main advantage of this generator type.

Rotational e.m.f. variation with speed is shown in Fig. 11. This e.m.f. is nearly constant through a very wide range of speed variation at high values of switched ON angle (alfa). The negative values of rotational e.m.f. are occurred in the low speed at motoring mode.

Self e.m.f. variation with speed is shown in Fig. 12.

At low values of switched ON angle (alfa), the self e.m.f. is increased by speed increasing. It will be decreased at high values of (alfa) and nearly constant at alfa $=30$ degree. This is due to the variation of rate of change of phase current $\left(\mathrm{dI}_{\mathrm{ph}} / \mathrm{dt}\right)$ with speed.

Variation of output power with speed is shown in Figure 13. High values of output power are obtained at low speeds with low values of (alfa), but with poor efficiency, as shown in Fig. 15. At high values of switched ON angle (alfa), the output power is decreased, but with high efficiency. The output power can be increased with high efficiency, by increasing the excitation voltage.

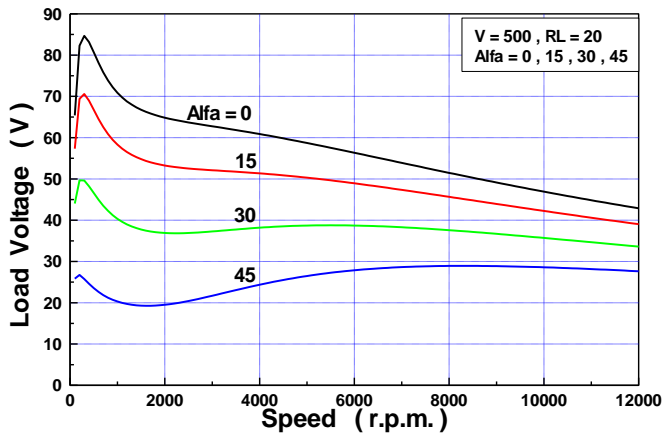

Fig. 10 Generator load voltage variation with speed at different values of switching $\mathrm{ON}$ angle

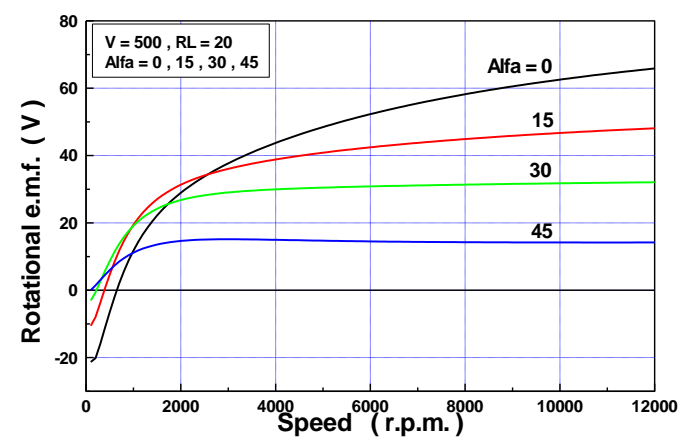

Fig. 11 Generator rotational e.m.f. variation with speed at different values of switching ON angle

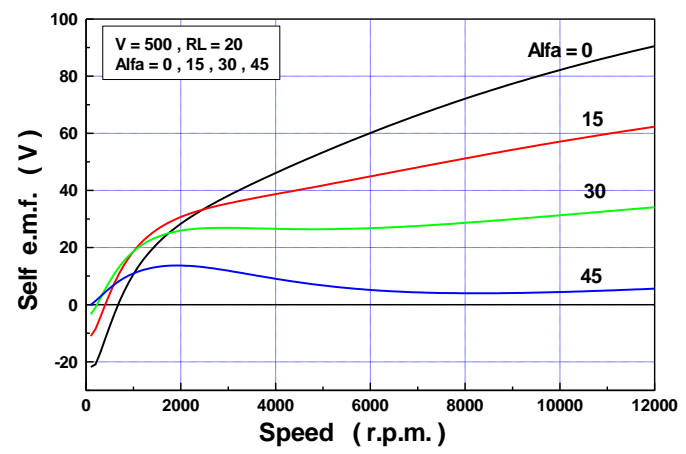

Fig.12 Generator self e.m.f. variation with speed at different values of switching $\mathrm{ON}$ angle

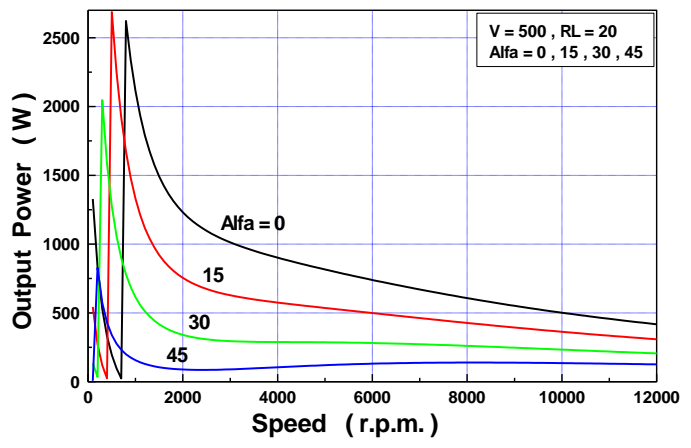

Fig. 13 Generator output power variation with speed at different values of switching $\mathrm{ON}$ angle 
Input power variation with speed is shown in Fig. 14. Input power is the summation of both mechanical and excitation powers. Input power is very high at low speed with low values of (alfa), and decreased with speed increasing.

Efficiency variation with speed is shown in Fig. 15. The generator efficiency is high through wide range of speed variation especially with high values of (alfa).

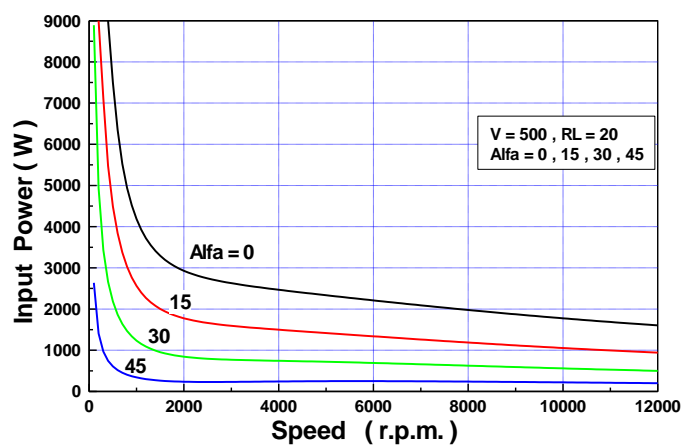

Fig. 14 Generator input power variation with speed at different values of switching $\mathrm{ON}$ angle

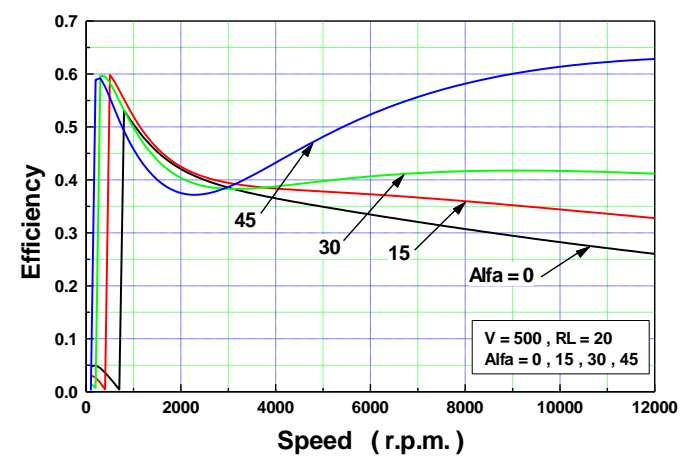

Fig. 15 Generator efficiency variation with speed at different values of switching $\mathrm{ON}$ angle

Input mechanical power variation with speed is shown in Fig. 16. This power is positive at low speed due to the operation of the machine as a motor. It becomes negative as a generator and nearly constant through wide range of high speeds.

Excitation power variation with speed is shown in Fig. 17. It is decreased to low values by speed and (alfa) increasing.

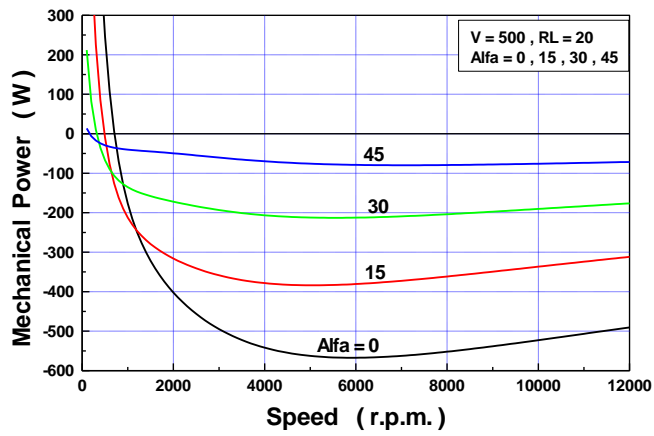

Fig. 16 Generator mechanical power variation with speed at different values of switching $\mathrm{ON}$ angle

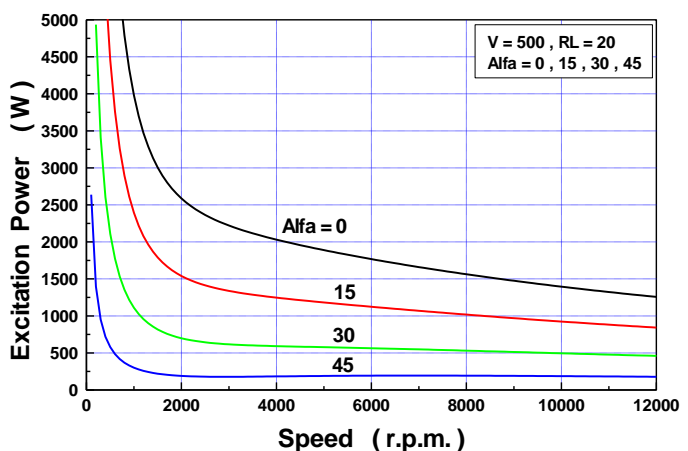

Fig. 17 Generator excitation power variation with speed at different values of switching $\mathrm{ON}$ angle

\section{CONCLUSIONS}

At high values of (alfa) which are preferred, the load voltage of a constant load resistance is nearly constant through very wide variation of speed. This is mainly due to the automatic decreasing of excitation current through speed increasing. This is the main advantage of this generator type. Rotational e.m.f. is nearly constant with speed variation. The output power can be increased with high efficiency, by increasing the excitation voltage.

\section{REFERENCES}

[1] S. R. MacMinn and J. W. Sember, "Control of a switched-reluctance aircraft starter/generator over a very wide speed range," in Proc. Intersociety Energy Conversion Engineering Conf., 1989, pp. 631-638.

[2] C.A Ferreira., S.R Jones, W.S. Heglund, W.D. Jones, "Detailed design of a $30-\mathrm{kW}$ switched reluctance starter/generator system for a gas turbine engine application" Industry Applications, IEEE Transactions on,Volume:31,Issue:3, May-June 1995.

[3] B. Fahimi, A. R.B. Emadi, Jr. Sepe, "A switched reluctance machine based starter/alternator for more electric cars" Energy Conversion, IEEE Transactions on,Volume:19, Issue:1, March 2004 Pages:116 - 124.

[4] M. A Mueller, "Design of low speed switched reluctance machines for wind energy converters"; Electrical Machines and Drives, 1999. Ninth International Conference on (Conf. Publ. No. 468), 1-3 Sept. 1999 Pages:60 - 64.

[5] A. Radun, "Generating with the switchedreluctance motor," in Proc. IEEE APEC'94, 1994, pp. 41-47. 
[6] Y. Sozer, D.A. Torrey, "Closed loop control of excitation parameters for high speed switchedreluctance generators", Power Electronics, IEEE Transactions on , Volume: 19, Issue: 2 , March 2004 Pages: 355 - 362.

[7] Asadi, P.; Ehsani, M.; Fahimi, B., "Design and control characterization of switched reluctance generator for maximum output power", TwentyFirst Annual IEEE Conference and Exposition on Applied Power Electronics, APEC'06, 19-23 March 2006,Pages:1639-1644.

[8] B. Fahimi, S. Dixon, "Enhancement of output electric power in switched reluctance generators", Electric Machines and Drives Conference, 2003, IEMDC'03. IEEE International, Volume: 2, 1-4 June 2003 Pages: $849-856$.

[9] Asadi, P.; Ehsani, M.; Fahimi, B., "Design and control characterization of switched reluctance generator for maximum output power", TwentyFirst Annual IEEE Applied Power Electronics Conference and Exposition, 2006, APEC '06, 1923 March 2006, Pages: 1639-1644.

[10] Nassereddine, M.; Rizk, J.; Nagrial, M.; Hellany,A., "Study analysis on the excitation of a switched reluctance generator for wind energy conversion", International Conference on Advances in Computational Tools for Engineering Applications, 2009, ACTEA '09, 15-17 July 2009, Pages:112-116.
[11] Fleury, A.; Andrade, D.; Silveira, A.W.F.V.; Ribeiro, F.S.L.; Coelho, "Dependence of the switched reluctance generator output on the speed and the excitation voltage", 34th Annual Conference of IEEE Industrial Electronics, IECON 2008, 10-13 Nov. 2008 Pages:11011105.

[12] Takahashi, Atsushi; Goto, Hiroki; Nakamura, "Characteristics of $8 / 6$ SR Generator with a Suppression Resistor Converter", 12th International Conference on Power Electronics and Motion Control, EPE-PEMC 2006, Aug. 30 2006-Sept. 12006 Pages:1037 - 1041.

\section{APPENDIX}

Excitation and load Currents

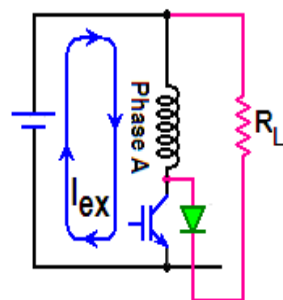

Excitation current

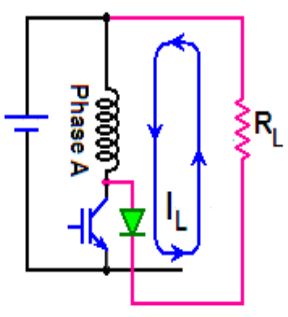

Load current
Generator Parameters

Rated current $=3 \mathrm{~A}, \mathrm{Rph}=4 \mathrm{Ohm}, \mathrm{R} \mathrm{L}=20 \mathrm{Ohm}$, $\mathrm{R} \mathrm{L}=20 \mathrm{Ohm}, \mathrm{L} \mathrm{d}=0.29 \mathrm{H}, \mathrm{L} \mathrm{d}=0.29 \mathrm{H}$, $\mathrm{L} \mathrm{q}=0.09 \mathrm{H}$, Stator phases $=3$, Stator cylindrical poles $=6$, Rotor salient poles $=2$ 